\title{
Characterization of Diaporthe species associated with peach constriction canker, with two novel species from China
}

\author{
Xianhong Wang', Yashuang Guo', Yamin Du', Ziling Yang', \\ Xinzhong Huang ${ }^{3}$, Ni Hong ${ }^{1,2}$, Wenxing $\mathrm{Xu}^{1,2}$, Guoping Wang ${ }^{1,2}$
}

I Key Lab of Plant Pathology of Hubei Province, College of Plant Science and Technology, Huazhong Agricultural University, Wuhan, Hubei, 430070, China $\mathbf{2}$ Key Laboratory of Horticultural Crop (Fruit Trees) Biology and Germplasm Creation of the Ministry of Agriculture, Wuhan, Hubei, 430070, China 3 Research Institute of Pomology, Fujian Academy of Agricultural Sciences, Fuzhou, Fujian, 350013, China

Corresponding author: Guoping Wang (gpwang@mail.hzau.edu.cn)

Academic editor: N. Boonyuen | Received 1 February 2021 | Accepted 29 April 2021 | Published 18 May 2021

Citation: Wang X, Guo Y, Du Y, Yang Z, Huang X, Hong N, Xu W, Wang G (2021) Characterization of Diaporthe species associated with peach constriction canker, with two novel species from China. MycoKeys 80: 77-90. https:// doi.org/10.3897/mycokeys.80.63816

\begin{abstract}
Species of Diaporthe infect a wide range of plants and live in vivo as endophytes, saprobes or pathogens. However, those in peach plants are poorly characterized. In this study, 52 Diaporthe strains were isolated from peach branches with buds, showing constriction canker symptoms. Phylogenetic analyses were conducted using five gene regions: internal transcribed spacer of the ribosomal DNA (ITS), translation elongation factor 1- $\alpha(T E F)$, ß-tubulin (TUB), histone (HIS), and calmodulin (CAL). These results coupled with morphology revealed seven species of Diaporthe, including five known species (D. caryae, D. cercidis, D. eres, D. hongkongensis, and D. unshiuensis). In addition, two novel species $D$. jinxiu and D. zaofenghuang are introduced. Except for the previously reported $D$. eres, this study represents the first characterization of Diaporthe species associated with peach constriction canker in China, and contributes useful data for practicable disease management.
\end{abstract}

\section{Keywords}

Constriction canker, Diaporthe, multi-gene phylogeny, Prunus persica, taxonomy, two new taxa

Copyright Xianhong Wang et al. This is an open access article distributed under the terms of the Creative Commons Attribution License (CC BY 4.0), which permits unrestricted use, distribution, and reproduction in any medium, provided the original author and source are credited. 


\section{Introduction}

The genus Diaporthe (asexual morph Phomopsis) was established by Nitschke in 1870 and predates its sexual morph established in 1905, thus Diaporthe is used for this genus (Rossman et al. 2015). The sexual morph of Diaporthe is characterized by black spherical ascomata with single or multiple tapering perithecial necks. Their asci are unitunicate, 8-spored, sessile, and elongate to clavate. The ascospores are hyaline, two-celled, often biguttulate, and elliptical to fusiform (Udayanga et al. 2015; Guo et al. 2020). The asexual morph is characterized by black or dark brown conidiomata, with cylindrical phialides producing three types of conidia (Udayanga et al. 2011; Gomes et al. 2013; Guo et al. 2020). In early studies, species of Diaporthe were identified based on host association, morphology and cultural characteristics (Uecker 1988). Recently, studies have shown that many species of Diaporthe are not host-specific i.e., one species may infect more than one host species, e.g., D. eres can infect blackberry (Vrandecic et al. 2011), pear (Bai et al. 2015), and jujube (Zhang et al. 2018). Moreover, a single species is prone to morphological changes depending on the incubation conditions (Gomes et al. 2013). Therefore, molecular data have been adopted to resolve the circumscription of species of Diaporthe, initially relying on the internal transcribed spacer (ITS) of the ribosomal DNA region (Santos et al. 2009; Thompson et al. 2011), and recently on multiple loci including ITS, translation elongation factor 1- $\alpha(T E F)$, ß-tubulin $(T U B)$, histone (HIS), and calmodulin (CAL) gene regions (Santos et al. 2017). At present, the five-locus dataset (ITS-TEFCAL-HIS-TUB) has been optimally adopted for the species delimitation by recent authors (Gao et al. 2017; Yang et al. 2018, 2020; Crous et al. 2020; Guo et al. 2020; Hyde et al. 2020; Sun et al. 2021).

Peach (Prunus persica L.) originated from China, where it has been cultivated for more than 3,000 years (Faust and Timon 2010). In the past ten years, the national annual production of peach and nectarine was 10-15 million tons, accounting for $50 \%$ of global production (http://www.fao.org/faostat/en/\#data/QC). In recent years, peach constriction canker has been frequently observed in peach orchards in Fujian province, one of the important peach-cultivation areas in China. This disease can cause flower bud necrosis, no flowering, and even kill the shoots, resulting in a severe economic loss for growers. Peach constriction canker was firstly observed in 1934 in New Jersey, USA (Daines et al. 1958), and usually infects peach buds leading to the formation of reddish-brown elongate cankers around twig nodes, which can girdle and kill buds the following summer (Lalancette and Robison 2001). In a previous study, P. amygdali was identified as the cause of peach constriction canker based on morphology in Spain (Tuset et al. 1989). However, morphology alone is not adequate for determining a species in Diaporthe. Moreover, Diaporthe spp. associated with peach plants have not been well documented. To understand the etiology of peach constriction canker in China, diseased samples were collected and isolates obtained from them. The characterization of these isolates revealed five known and two novel Diaporthe species associated with the disease. 


\section{Materials and methods}

\section{Sampling and isolation}

The infected peach branches with buds showing constriction canker symptoms were collected in Fujian province of China in 2017-2018. The collected samples were subjected to fungal isolation following the protocol described by Bai et al. (2015). Diseased tissues $\left(4-5 \mathrm{~mm}^{2}\right)$ were excised from infected bud scales after they were surface-sterilized with $75 \%$ ethanol for $45 \mathrm{~s}$ and $1 \% \mathrm{NaOCl}$ for $45 \mathrm{~s}$, rinsed twice with sterilized water, and air-dried. The excised tissues were placed on potato dextrose agar (PDA, $20 \%$ diced potatoes, $2 \%$ dextrose and $1.5 \%$ agar) plates and incubated at $25^{\circ} \mathrm{C}$ in the dark for 3-5 d. After colonies grow, their mycelium was transferred to a new PDA plate and each colony was designated as a specific isolate. Each isolate was further purified by culturing from a single conidium (Choi et al. 1999). The obtained isolates were stored in $25 \%$ glycerol at $-80^{\circ} \mathrm{C}$ for further usage. Specimens of new species were deposited in the Mycological Herbarium, Institute of Microbiology, Chinese Academy of Sciences, Beijing, China (HMAS). Ex-type living cultures were deposited in the China General Microbiological Culture Collection Centre (CGMCC), Beijing, China. Sequences of the novel species were submitted to MycoBank (http://www.mycobank.org).

\section{Morphological analyses}

Fungal morphology was determined by culturing a 5 -d-old mycelial disc $(5 \mathrm{~mm}$ in diameter) on a petri dish containing PDA and oatmeal agar (OA) (Udayanga et al. 2014), respectively. Cultures were incubated at $25^{\circ} \mathrm{C}$ with a $14 / 10 \mathrm{~h}$ fluorescent light/ dark cycle. Growth rate $(\mathrm{mm} / \mathrm{d})$ was determined by measuring the colony diameters of each isolate on PDA daily for 3 days. The colony morphologies were recorded after $14 \mathrm{~d}$. Moreover, the shape, color, and size of conidiomata, conidia and conidiophore were observed using an optical microscope (Olympus BX63 or Olympus SZX16, Japan), and 50 conidia of each isolate were measured to determine their size.

\section{DNA extraction and determination of the taxonomic region sequences}

Genomic DNA was extracted from pure culture using modified cetyltrimethyl-ammonium bromide (CTAB) protocol (Udayanga et al. 2012), and subjected to PCR amplification of the partial regions of the five loci comprised ITS, TUB, TEF, CAL, and HIS using corresponding primer pairs: ITS5/ITS4 (White et al. 1990), Bt2a/Bt2b (Glass and Donaldson 1995), EF1-728F/EF1-986R (Carbone and Kohn 1999), CAL-228F/CAL-737R (Carbone and Kohn 1999), and CYLH3F/H3-1b (Glass and Donaldson 1995, Crous et al. 2006), respectively. PCR programs were initiated with $95^{\circ} \mathrm{C}$ for $5 \mathrm{~min}$, followed by 34 cycles of denaturation at $95^{\circ} \mathrm{C}$ for $30 \mathrm{~s}$, annealing at a suitable temperature for $30 \mathrm{sec}$ $\left(56^{\circ} \mathrm{C}\right.$ for ITS, $52^{\circ} \mathrm{C}$ for $T E F, 54^{\circ} \mathrm{C}$ for $C A L, 57^{\circ} \mathrm{C}$ for $H I S$ and $60^{\circ} \mathrm{C}$ for $T U B$ ), and extension at $72^{\circ} \mathrm{C}$ for $30 \mathrm{sec}$, and terminated with a final elongation step at $72^{\circ} \mathrm{C}$ for $10 \mathrm{~min}$. 
The PCR amplicons were purified and sequenced at the Sangon Biotech (Shanghai, China) Company. Consensus sequences were obtained using DNAMAN (v. 9.0, Lynnon Biosoft), and deposited in GenBank (Suppl. material 1: Table S1).

\section{Phylogenetic analyses}

Sequences generated in this study were blasted against the NCBI GenBank nucleotide database to determine the closest relatives. Alignment of different gene regions of isolates obtained in this study, their relatives and the ones of the type species (Suppl. material 2: Table S2) was initially performed using the MAFFT v. 7 online servers (http:// mafft.cbrc.jp/alignment/server/index.html) (Katoh and Standley 2013) with default settings, and the alignment was manually adjusted in MEGA v. 7 (Kumar et al. 2016).

Phylogenetic analyses were conducted based on the concatenated five loci. Bayesian inference (BI) was used to construct phylogenies using MrBayes v. 3.1.2 (Ronquist and Huelsenbeck 2003). The best-fit model of nucleotide substitution for each partition was determined using MrModeltest v. 2.3 (Nylander 2004) and incorporated into the analyses. Two analyses of four Markov Chain Monte Carlo (MCMC) chains were conducted from random trees with $1.8 \times 10^{8}$ generations. The analyses were sampled every 1,000 generations, which were stopped once the average standard deviation of split frequencies was below 0.01 . The first $25 \%$ of the trees were discarded as the burnin phase of each analysis, and the remaining trees were summarized to calculate the posterior probabilities (PP) of each monophyletic clade.

Additionally, maximum parsimony analyses (MP) were performed on the multi-locus alignment using PAUP (Phylogenetic Analysis Using Parsimony) v. 4.0b10 (Swofford 2002). Phylogenetic trees were generated using the heuristic search option with Tree Bisection Reconnection (TBR) branch swapping and 1,000 random sequence additions. Max trees were set up to 5,000, zero-length branches were collapsed, and all multiple parsimonious trees were saved. Clade stability was assessed using a bootstrap analysis with 1,000 replicates. Tree length (TL), consistency index (CI), retention index (RI), rescaled consistency index (RC), and homoplasy index (HI) were calculated. Furthermore, maximum likelihood (ML) analysis was performed using IQtree v. 1.6.8. The analysis was performed with a GTR site substitution model. Branch support was evaluated with a bootstrapping (BS) method of 1,000 replicates (Hillis and Bull 1993). Phylogenetic trees were visualized in FigTree v. 1.4.2 (Rambaut 2014). The alignments and phylogenetic trees were deposited in TreeBASE (submission ID: 28014).

\section{Results}

\section{Collection of Diaporthe strains}

In the surveyed orchards, this disease caused flower-bud necrosis, little or no flowering (Fig. 1A), black-brown lesions around the buds (Fig. 1B), petrified blossom buds 

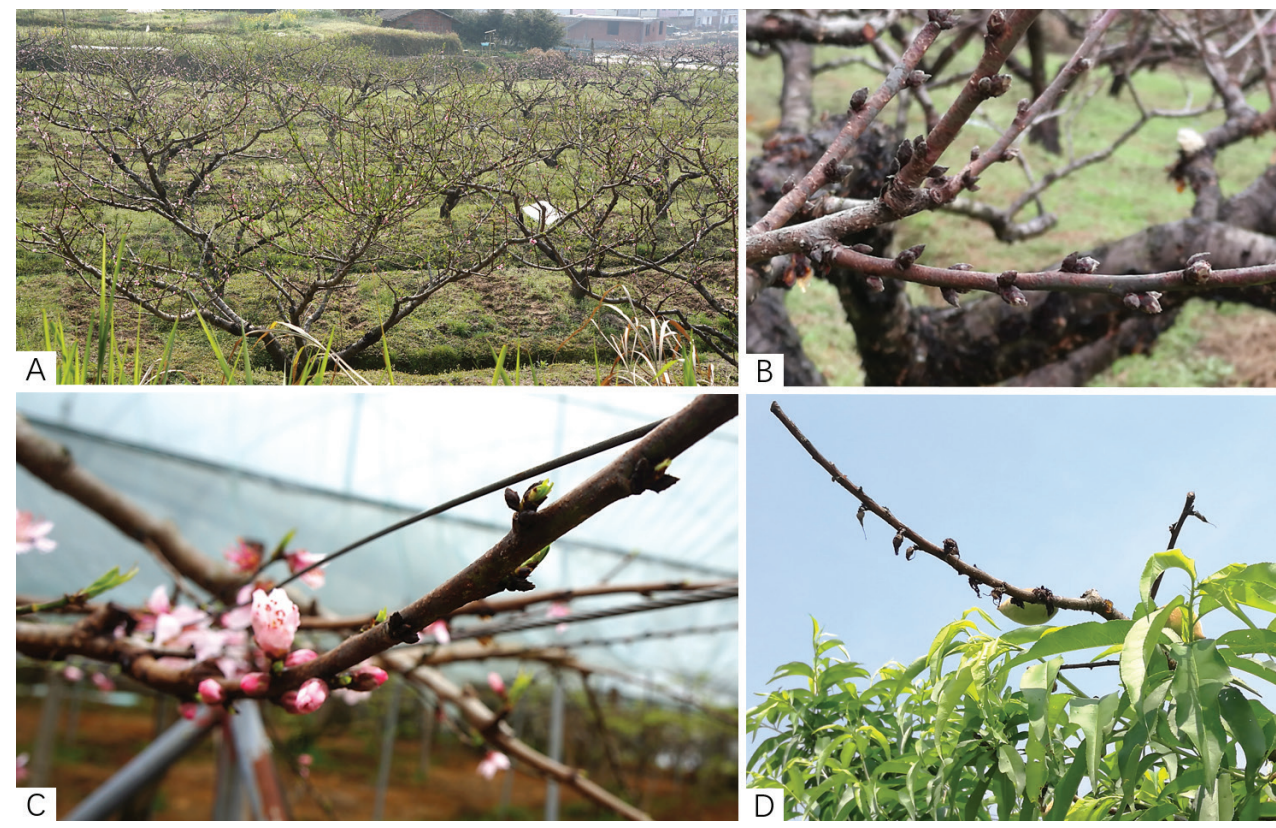

Figure I. Representative symptoms of peach constriction canker in the field $\mathbf{A}$ blossom bud necrosis, few or no flowers on peach trees in spring $\mathbf{B}$ black-brown lesions around buds $\mathbf{C}$ petrified blossom buds D rigid leaf buds.

(Fig. 1C), and rigid leaf buds (Fig. 1D). A total of 52 Diaporthe strains were obtained from 27 infected bud samples of Prunus persica cultivars (cvs.) Baifeng, Jinxiu, Jinyuan, and Zaofenghuang by fungal isolation and single spore culturing. All strains were used in morphological observation and phylogenetic analysis.

\section{Phylogenetic analyses}

The strains mentioned above together with 49 reference isolates of previously described species (Suppl. material 2: Table S2) were subjected to multi-locus phylogenetic analyses with concatenated ITS, TEF, CAL, HIS, and TUB sequences. Diaporthella corylina (CBS 121124) was selected as the outgroup. A total of 2,514 characters of nucleotides and gaps (ITS: 1-578, TEF: 579-960, CAL: 961-1,469, HIS: 1,470-1,989, TUB: 1,990-2,514) were included in the phylogenetic analysis. The maximum-likelihood (ML) tree was generated with the GTR model. The best nucleotide substitution models were recommended by MrModeltest and used in the Bayesian analysis: $\mathrm{SYM}+\mathrm{I}+\mathrm{G}$ for ITS, GTR+G for TEF, $\mathrm{HKY}+\mathrm{I}+\mathrm{G}$ for $T U B$, and GTR+I+G for both $C A L$ and HIS. The heuristic search using MP generated 1,000 parsimonious trees $(\mathrm{TL}=3,182, \mathrm{CI}=0.52, \mathrm{RI}=0.87, \mathrm{RC}=0.45)$, and branches of zero length were collapsed and all multiple parsimonious trees were saved. MP and ML bootstrap support values above $50 \%$ are shown as second and third position 


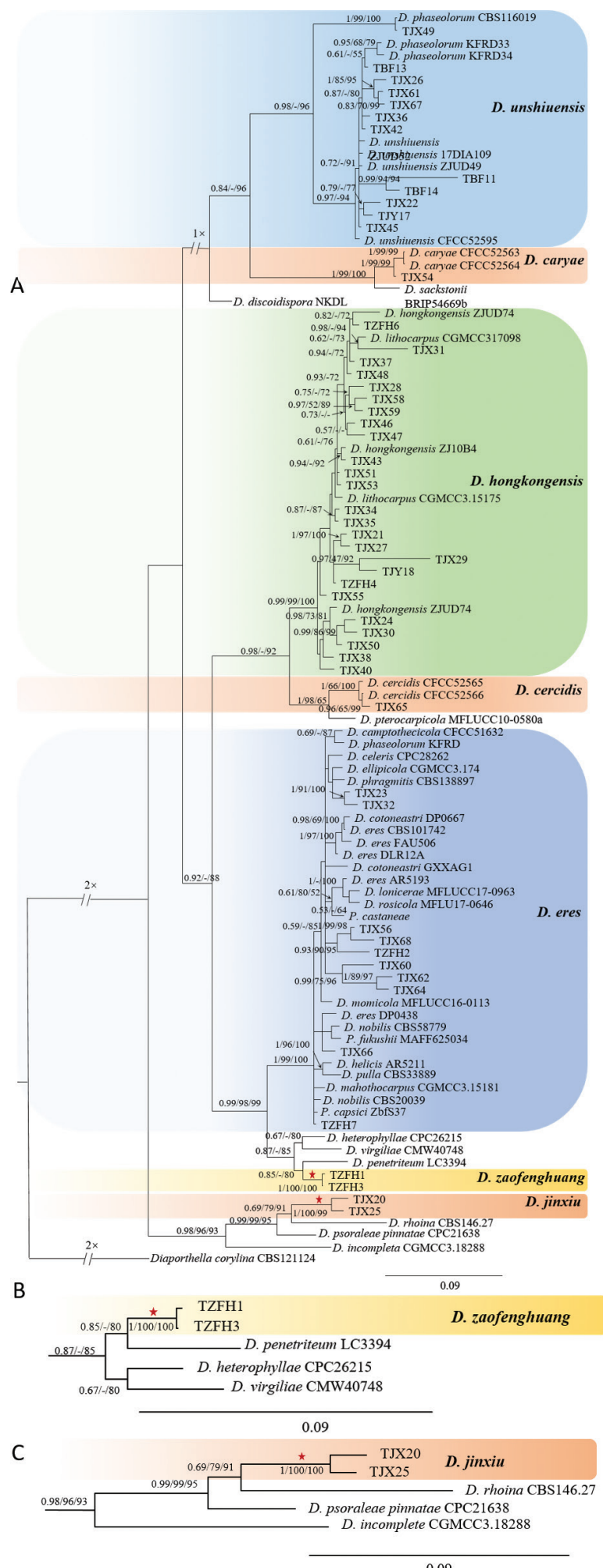


above the nodes, respectively. In the phylogenetic tree, 48 of the 52 isolates obtained in this study were assigned to five known species, D. caryae (one strain), D. cercidis (one), D. eres (nine), D. hongkongensis (26), and D. unshiuensis (11). Four strains formed two distinct clades, and were identified as two novel species, described herein as D. zaofenghuang (two strains, closely related to D. penetriteum), and D. jinxiu (two strains, close to D. rhoina), respectively (Fig. 2).

\section{Taxonomy}

\section{Diaporthe jinxiu X.H. Wang \& G.P. Wang, sp. nov.}

MycoBank No: 838502

Fig. 3

Etymology. Named for the host variety (Prunus persica cv. Jinxiu), from which the species was isolated.

Description. Sexual morph: not observed. Asexual morph on alfalfa stems after 15 days. Pycnidial conidiomata small, covered by pale yellow discharged conidial masses at maturity, 385-810 $\mu \mathrm{m}$ diam. Conidiophore hyaline, cylindrical, smooth, phialidic, unbranched, straight or slightly curved, $16-21 \times 2-2.5 \mu \mathrm{m}$. Conidiogenous cells phialidic, cylindrical. Alpha conidia hyaline, aseptate, ellipsoidal, biguttulate, rounded at each end, 5.8-7.1 $\times 2.7-4.0 \mu \mathrm{m}($ mean $=6.4 \pm 0.4 \times 3.5 \pm 0.3 \mu \mathrm{m}, \mathrm{n}=50)$. Beta and gamma conidia not observed.

Culture characteristics. Cultures incubated on PDA at $25^{\circ} \mathrm{C}$ in cycle of light/ darkness, growth rate $11.5 \mathrm{~mm}$ per day. On PDA medium, colonies were sparse and villous, flourishing at edge of colony. On OA medium, colonies dense with neat edges, with yellow pigment in the center.

Materials examined. China, Fujian Province, Sanming City, on buds of Prunus persica cv. Zaofenghuang, 23 March 2017, Y. S. Guo (holotype HMAS 249837, culture ex-holotype culture CGMCC3.20269 = TZFH20); ibid., ex-isotype culture TZFH25.

Notes. In the phylogenetic, multi-locus tree, $D$. jinxiu forms a distinct clade with maximum support $(1 / 100 / 99)$ and is most closely related to $D$. rhoina, but with smaller pycnidial conidiomata than the later $(D$. jinxiu $=386-807 \mu \mathrm{m}$ vs $D$. rhoina $=500$ $2500 \mu \mathrm{m})($ Feltgen 1901). Moreover, the sequence differences were significant, and all five regions were able to distinguish them (28/578 in ITS, 38/382 in TEF, 21/509 in CAL, 28/520 in HIS, and 11/525 in TUB).

Figure 2. A phylogenetic tree generated by Bayesian analysis based on combined ITS, TEF, CAL, HIS, and TUB sequence. Diaporthella corylina (CBS121124) was selected as the outgroup. Bayesian posterior probability ( $\mathrm{PP} \geq 0.90$ ), MP bootstrap support values ( $\mathrm{MP} \geq 50 \%$ ) and RAxML bootstrap support values $(\mathrm{ML} \geq 50 \%)$ are shown at the nodes (PP/ML/MP). The branches of the new Diaporthe species are marked with red stars $\mathbf{B}, \mathbf{C}$ are partial phylogenetic taxa highlighting $D$. zaofenghuang and $D$. jinxiu together with their closely related species, respectively. 


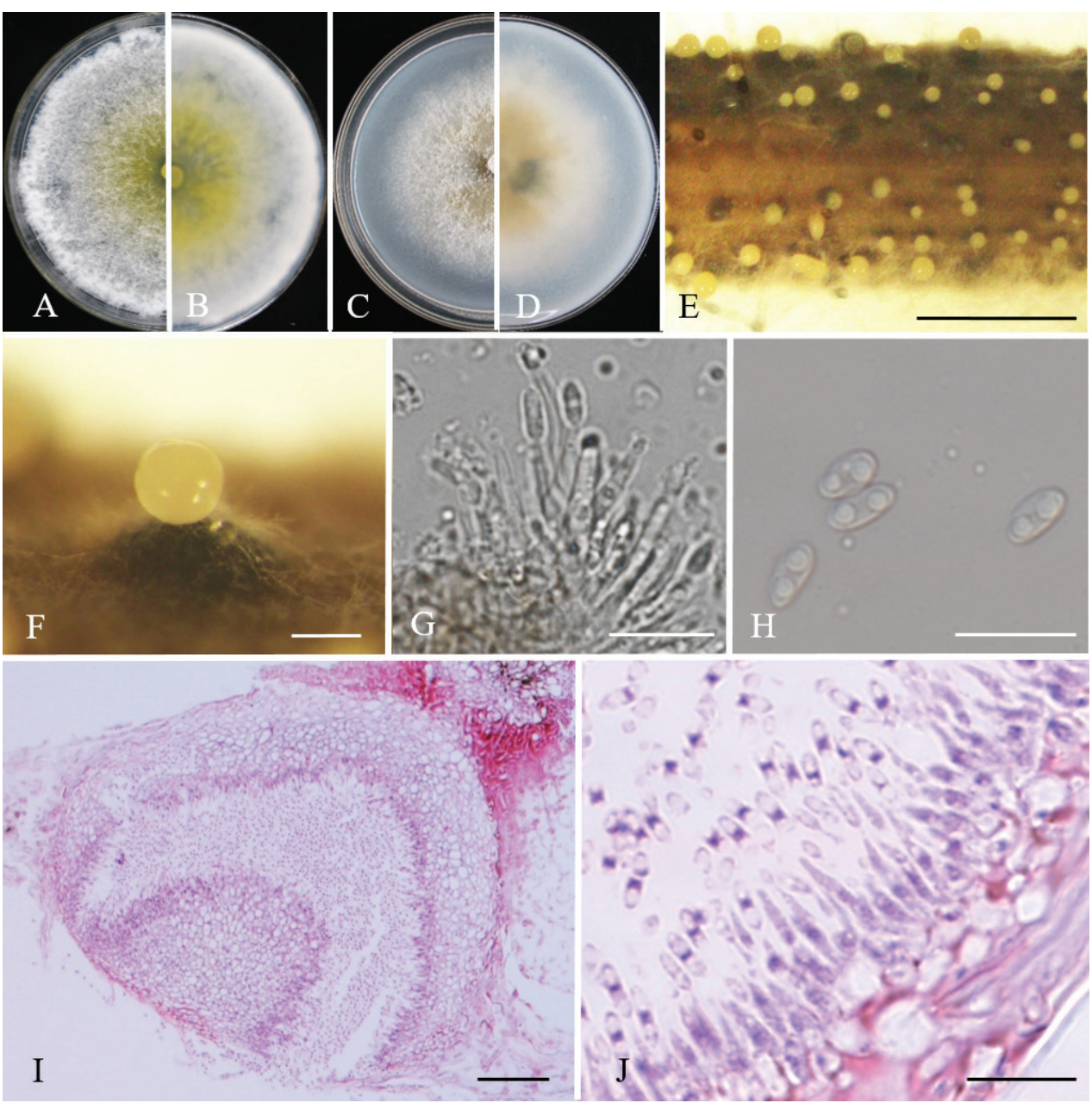

Figure 3. Diaporthe jinxiu. Front and back views of colonies on PDA (A, B) and OA $(\mathbf{C}, \mathbf{D})$, respectively $\mathbf{E}$ conidiomata on alfalfa stems $\mathbf{F}$ conidioma $\mathbf{G}$ conidiophores $\mathbf{H}$ alpha conidia I-J section view of conidioma. Scale bars: $2 \mathrm{~mm}(\mathbf{E}) ; 200 \mu \mathrm{m}(\mathbf{F}) ; 20 \mu \mathrm{m}(\mathbf{I}) ; 10 \mu \mathrm{m}(\mathbf{G}, \mathbf{H}, \mathbf{J})$.

\section{Diaporthe zaofenghuang X.H. Wang \& G.P. Wang, sp. nov.}

MycoBank No: 838501

Fig. 4

Etymology. Named after the host species (Prunus persica cv. Zaofenghuang) from which the species was isolated.

Description. Sexual morph not observed. Asexual morph on alfalfa stems. Pycnidial conidiomata conical, yellowish translucent conidial drops exuded from ostioles, 650-1430 $\mu \mathrm{m}$ diam. Conidiophores fasciculate, hyaline, long cylindrical, straight or slightly curved, apex pointed, 13.7-20.9 × 1.8-2.7 $\mu \mathrm{m}$. Conidiogenous cells phialidic, cylindrical. Alpha conidia hyaline, aseptate, ellipsoidal, biguttulate, rounded at one 

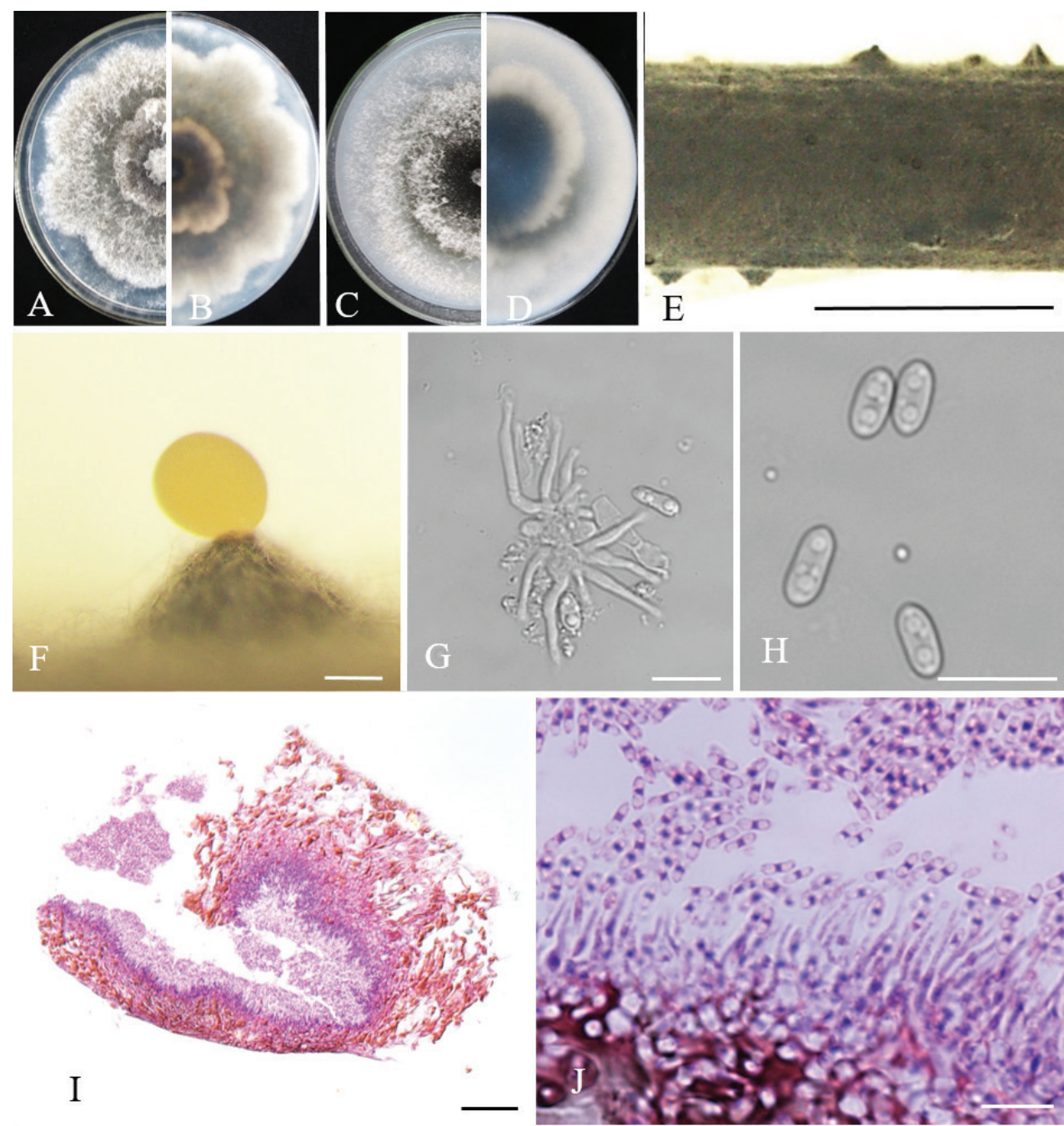

Figure 4. Diaporthe zaofenghuang. Front and back views of colonies on PDA (A, B) and OA (C, D), respectively $\mathbf{E}$ conidiomata on alfalfa stems $\mathbf{F}$ conidioma $\mathbf{G}$ conidiophores $\mathbf{H}$ alpha conidia $\mathbf{I}-\mathbf{J}$ section view of conidioma. Scale bars: $2 \mathrm{~mm}(\mathbf{E}) ; 200 \mu \mathrm{m}(\mathbf{F}) ; 20 \mu \mathrm{m}(\mathbf{G}, \mathbf{I}) ; 10 \mu \mathrm{m}(\mathbf{H}, \mathbf{J})$.

end, slightly apex at another end, 5.3-7.5 × 2.9-3.7 $\mu \mathrm{m}($ mean $=6.0 \pm 0.6 \times 3.1 \pm$ $0.3 \mu \mathrm{m}, \mathrm{n}=50)$. Beta and gamma conidia not observed.

Culture characteristics. Cultures incubated on PDA at $25^{\circ} \mathrm{C}$ in cycle of light/ darkness, growth rate $8.5 \mathrm{~mm}$ per day. Colonies initially white on surface, producing black pigment from center of medium and expanding outwardly after 5-7 d. On PDA, edge of colony petal-like, irregular; on OA, edge relatively flat.

Materials examined. China, Fujian Province, Sanming City, on buds of Prunus persica cv. Zaofenghuang, 23 March 2017, Y. S. Guo (holotype HMAS 249835, culture ex-holotype CGMCC3.20271 = TZFH1); ibid., culture TZFH3. 
Notes. Two isolates representing D. zaofenghuang form a well-supported clade $(1 / 100 / 100)$ and appear to be most closely related to $D$. penetriteum. Diaporthe zaofenghuang can be distinguished from $D$. penetriteum based on ITS, HIS, and TUB loci (10/578 in ITS, 45/520 in HIS, and 7/525 in TUB). Morphologically, D. zaofenghuang differs from $D$. penetriteum in having larger conidiomata $(D$. zaofenghuang = 653-1433 $\mu \mathrm{m}$ vs $D$. penetriteum $=180-490 \mu \mathrm{m})$ and alpha conidia $(D$. zaofenghuang $=6.0 \pm 0.6 \times 3.1 \pm 0.3 \mu \mathrm{m}$ vs $D$. penetriteum $=5.0 \pm 0.3 \times 2.2 \pm 0.2 \mu \mathrm{m})$. Additionally, $D$. penetriteum produces two types of conidia, but $D$. zaofenghuang produces only alpha conidia (Gao et al. 2016).

\section{Discussion}

In this study, phylogenetic analyses based on the five combined loci (ITS, TEF, CAL, $H I S$, and $T U B$ ) coupled with morphology revealed seven Diaporthe species (viz. D. caryae, D. cercidis, D. eres, D. hongkongensis, D. jinxiu, D. unshiuensis, and D. zaofenghuang) associated with peach constriction canker. Of these species, two novel species D. jinxiu and D. zaofenghuang in distinct clades were described. Diapothe jinxiu has smaller conidiomata as compared to its closest relative D. rhoina. However, it is not possible to have more morphological comparisons at this stage because limited biological information is available for this species (Feltgen 1901). Moreover, D. jinxiu clearly differs from other phylogenetically related species, e.g., D. psoraleae-pinnatae, by having shorter and wider alpha conidia (D. jinxiu $=5.8-7.1 \times 2.7-4.0 \mu \mathrm{m}$ vs D. psoraleae-pinnatae $=7.0-12.0 \times 2.5-3.0 \mu \mathrm{m})$ (Crous et al. 2013), and yellow pigments (Fig. 3A-D). Diaporthe zaofenghuang showed different morphologies compared with D. penetriteum, e.g., larger alpha conidia, larger conidiomata, and no beta conidia (Gao et al. 2016). Therefore, both novel species described here are clearly separated from known ones in the phylogeny and morphology.

Based on molecular data, several Diaporthe species associated with peach diseases in other countries have been identified and characterized, including D. amygdali, which is responsible for apical dead shoot, twig and shoot blight in peach and nectarine in Uruguay (Sessa et al. 2017), and D. eres for stem canker on peach in Italy and Greece (Thomidis et al. 2009; Prencipe et al. 2017). Diaporthe amygdali was not found in the present study but Dai et al. (2012) recorded it as Phomopsis amygdali related to twig canker of peach. Previously, six Diaporthe spp. infecting peach trees have been characterized in China. The reported D. hongkongensis caused fruit rot (Zhang et al. 2021), D. eres, D. momicola, D. pescicola, and D. taoicola were related to tree dieback (Dissanayake 2017), and D. amygdali was related to twig canker (Dai et al. 2012). To our knowledge, besides $D$. eres, this is the first report of $D$. caryae, $D$. cercidis, $D$. hongkongensis, D. jinxiu, D. unshiuensis, and D. zaofenghuang as the cause of peach constriction canker. This study contributes useful information for practicable disease management.

Previous studies have revealed that species of Diaporthe are highly divergent and closely linked to sampling areas, such as 19 species of Diaporthe infecting pears cultivated in 15 provinces of China (Guo et al. 2020). Further studies are required to 
include an extensive collection of Diaporthe isolates from other peach-cultivated regions in China. For effective disease management, more knowledge is required about Diaporthe species related to peach constriction canker in China.

\section{Acknowledgements}

This work was financially supported by the earmarked fund for the China Agriculture Research System (CARS-28) and the Key National Project (no. 2018YFD0201406). The authors would like to thank Dr. Xiang Li, Canadian Food Inspection Agency, for helping to improve the English in the manuscript.

\section{References}

Bai Q, Zhai LF, Chen XR, Hong N, Xu WX, Wang GP (2015) Biological and molecular characterization of five Phomopsis species associated with pear shoot canker in China. Plant Disease 99: 1704-1712. https://doi.org/10.1094/PDIS-03-15-0259-RE

Carbone I, Kohn LM (1999) Method for designing primer sets for speciation studies in filamentous ascomycetes. Mycologia 91: 553-556. https://doi.org/10.1080/00275514.1999 .12061051

Choi YW, Hyde KD, Ho WH (1999) Single spore isolation of fungi. Fungal Diversity 3: 29-38. https://www.researchgate.net/publication/228482364.

Crous PW, Groenewald JZ, Risede JM, Simoneau P, Hywel-Jones NL (2006) Calonectria species and their Cylindrocladium anamorphs: species with clavate vesicles. Studies in Mycology 55: 213-226. https://doi.org/10.3114/sim.55.1.213

Crous PW, Wingfield MJ, Guarro J, Cheewangkoon R, van der Bank M, Swart WJ, Stchige AM, Cano-Lira JF, Roux J, Madrid H, Damm U, Wood AR, Shuttleworth LA, Hodges CS, Munster M, de Jesús Yáńez-Morales M, Zúńiga LE, Cruywagen EM, De Hoog G, Silvera C, Najafzadeh J, Davison EM, Davison PJN, Barrett MD, Barrett RL, Manamgoda DS, Minnis AM, Kleczewski NM, Flory SL, Castlebury LA, Clay K, Hyde KD, MaússeSitoe SND, Shuaifei Chen, Lechat C, Hairaud M, Lesage-Meessen L, Pawłowska J, Wilk M, Śliwińska-Wyrzychowska A, Mętrak M, Wrzosek M, Pavlic-Zupanc D, Maleme HM, Slippers B, Mac Cormack WP, Archuby DI, Grünwald NJ, Tellería MT, Dueñas M, Martín MP, Marincowitz S, de Beer ZW, Perez CA, Gené J, Marin-Felix Y, Groenewald JZ (2013) Fungal Planet description sheets: 154-213. Persoonia 31: 188-296. https://doi. org/10.3767/003158513X675925

Crous PW, Wingfield MJ, Schumacher RK, Akulov A, Bulgakov TS, Carnegie AJ, Jurjević Ž, Decock C, Denman S, Lombard L (2020) New and interesting fungi. 3. Fungal Systematics and Evolution 6: 157-231. https://doi.org/10.3114/fuse.2020.06.09

Dai FM, Zeng R, Lu JP (2012) First report of twig canker on peach caused by Phomopsis amygdali in China. Plant Disease 96: 288-289. https://doi.org/10.1094/PDIS-04-11-0321

Daines RH, Cohoon DF, Leone I, Brennan E (1958) Control of Fusicoccum canker of peach by nutrition, defoliation, and protective fungicides. Phytopathology 48: 400-407. 
Dissanayake AJ, Zhang W, Liu M, Hyde KD, Zhao WS, Li XH, Yan JY (2017) Diaporthe species associated with peach tree dieback in Hubei, China. Mycosphere 8: 533-549. https:// doi.org/10.5943/mycosphere/8/5/2

Faust M, Timon BL (1995) Origin and dissemination of peach. Horticultural Reviews 17: 331-379. https://doi.org/10.1002/9780470650585.ch10

Feltgen J (1901) Vorstudien zu einer Pilz-Flora des grossherzogthums Luxemburg, I. Theil. Ascomycetes, Nachträge II. Worré-Mertens, Luxemburg, 145 pp. https://www.biodiversitylibrary.org/page/2895947\#page/831/mode/1up

Gao YH, Fang Liu F, Cai L (2016) Unravelling Diaporthe species associated with Camellia, Systematics and Biodiversity 14: 102-117. https://doi.org/10.1080/14772000.2015.1 101027

Gao YH, Liu F, Duan W, Crous PW, Cai L (2017) Diaporthe is paraphyletic. IMA Fungus 8: 153-187. https://doi.org/10.5598/imafungus.2017.08.01.11

Glass NL, Donaldson GC (1995) Development of primer sets designed for use with the PCR to amplify conserved genes from filamentous ascomycetes. American Society for Microbiology 61: 1323-1330. https://doi.org/10.1128/AEM.61.4.1323-1330.1995

Gomes RR, Glienke C, Videira SIR, Lombard L, Groenewald JZ, Crous PW (2013) Diaporthe: a genus of endophytic, saprobic and plant pathogenic fungi. Persoonia 31: 1-41. https:// doi.org/10.3767/003158513X666844

Guo YS, Crous PW, Bai Q, Fu M, Yang MM, Wang XH, Du YM, Hong N, Xu WX, Wang GP (2020) High diversity of Diaporthe species associated with pear shoot canker in China. Persoonia: 132-162. https://doi.org/10.3767/persoonia.2020.45.05

Hillis DM, Bull JJ (1993) An empirical test of bootstrapping as a method for assessing confidence in phylogenetic analysis. Systematic Biology 42: 182-192. https://doi. org/10.2307/2992540

Hyde KD, Dong Y, Phookamsak R, Jeewon R, Bhat DJ, Gareth Jones EB, Liu NG, Abeywickrama PD, Mapook A, Wei D (2020) Fungal diversity notes 1151-1276: taxonomic and phylogenetic contributions on genera and species of fungal taxa. Fungal Diversity 100: 1-273. https://doi.org/10.1007/s13225-020-00439-5

Katoh K, Standley DM (2013) MAFFT multiple sequence alignment software version 7: improvements in performance and usability. Molecular Biology and Evolution 30: 772-780. https://doi.org/10.1093/molbev/mst010

Kumar S, Stecher G, Tamura K (2016) MEGA7: Molecular evolutionary genetics analysis version 7.0 for bigger datasets. Molecular Evolutionary Genetics Analysis 33: 1870-1874. https://doi.org/10.1093/molbev/msw054

Lalancette N, Robison DM (2001) Seasonal availability of inoculum for constriction canker of peach in New Jersey. Phytopathology 91: 1109-1115. https://doi.org/10.1094/PHYTO.2001.91.11.1109

Nitschke T (1870) Pyrenomycetes Germanici 2. Eduard Trewendt, Breslau, 245 pp.

Nylander JAA (2004) MrModelTest v. 2. Program distributed by the author. Evolutionary Biology Centre, Uppsala University.

Prencipe S, Nari L, Vittone G, Spadaro D (2017) First report of Diaporthe eres causing stem canker on peach (Prunus persica) in Italy. Plant Disease 101: e1052. https://doi.org/10.1094/ PDIS-12-16-1770-PDN 
Rambaut A (2014) FigTree, v. 1.4.2. Institute of evolutionary biology. University of Edinburgh. http://tree.bio.ed.ac.uk/software/figtree/

Ronquist F, Huelsenbeck JP (2003) MrBayes 3: Bayesian phylogenetic inference under mixed models. Bioinformatics 19: 1572-1574. https://doi.org/10.1093/bioinformatics/btg180

Rossman AY, Adams GC, Cannon PF, Castlebury LA, Crous PW, Gryzenhout M, Jaklitsch WM, Mejia LC, Stoykov D, Udayanga D, Voglmayr H, Walker DM (2015) Recommendations of generic names in Diaporthales competing for protection or use. IMA Fungus 6: 145-154. https://doi.org/10.5598/imafungus.2015.06.01.09

Santos JM, Phillips AJL (2009) Resolving the complex of Diaporthe (Phomopsis) species occurring on Foeniculum vulgare in Portugal. Fungal Diversity 34: 109-123.

Santos L, Alves A, Alves R (2017) Evaluating multi-locus phylogenies for species boundaries determination in the genus Diaporthe. PeerJ 5: e3120. https://doi.org/10.7717/peerj.3120

Sessa L, Abreo E, Bettucci L, Lupo S (2017) Diversity and virulence of Diaporthe species associated with wood disease symptoms in deciduous fruit trees in Uruguay. Phytopathologia Mediterranea 56: 431-444. https://doi.org/10.14601/Phytopathol_Mediterr-20678

Sun W, Huang S, Xia J, Zhang X, Li Z (2021) Morphological and molecular identification of Diaporthe species in south-western China, with description of eight new species. MycoKeys 77: 65-95. https://doi.org/10.3897/mycokeys.77.59852

Swofford D (2002) PAUP 4.0 b10: Phylogenetic analysis using parsimony (*and other methods). Computer programmer. Sinauer Associates, Sunderland.

Thomidis T, Michailides TJ (2009) Studies on Diaporthe eres as a new pathogen of peach trees in Greece. Plant Disease 1293-1297. https://doi.org/10.1094/PDIS-93-12-1293

Thompson SM, Tan YP, Young AJ, Neate SM, Aitken EA, Shivas RG (2011) Stem cankers on sunflower (Helianthus annuus) in Australia reveal a complex of pathogenic Diaporthe (Phomopsis) species. Persoonia 27: 80-89. https://doi.org/10.3767/003158511X617110

Tuset JJ, Portilla MT (1989) Taxonomic status of Fusicoccum amygdali and Phomopsis amygdalina. Canadian Journal of Botany 67: 1275-1280. https://doi.org/10.1139/b89-168

Udayanga D, Liu XZ, McKenzie EHC, Chukeatirote E, Bahkali AH, Hyde KD (2011) The genus Phomopsis: biology, applications, species concepts and names of common phytopathogens. Fungal Diversity 50: 189-225. https://doi.org/10.1007/s13225-011-0126-9

Udayanga D, Liu XZ, Crous PW, McKenzie EHC, Chukeatirote E, Hyde KD (2012) A multilocus phylogenetic evaluation of Diaporthe (Phomopsis). Fungal Diversity 56: 157-171. https://doi.org/10.1007/s13225-012-0190-9

Udayanga D, Castlebury LA, Rossman AY, Hyde KD (2014) Species limits in Diaporthe: molecular re-assessment of $D$. citri, D. cytosporella, D. foeniculina and D. rudis. Persoonia 32: 83-101. https://doi.org/10.3767/003158514X679984

Udayanga D, Castlebury LA, Rossman AY, Chukeatirote E, Hyde KD (2015) The Diaporthe sojae species complex: Phylogenetic reassessment of pathogens associated with soybean, cucurbits and other field crops. Fungal Biology 119:383-407. https://doi.org/10.1016/j.funbio.2014.10.009

Uecker FA (1988) A world list of Phomopsis names with notes on nomenclature, morphology and biology. Mycological Memoirs 13: 1-231.

Vrandecic K, Jurkovic D, Cosic J, Postic J, Riccioni L (2011) First report of cane blight on blackberry caused by Diaporthe eres in Croatia. Plant Disease 95: 612-612. https://doi. org/10.1094/PDIS-11-10-0860 
White TJ, Bruns S, Lee S, Taylor J (1990) Amplification and direct sequencing of fungal ribosomal RNA genes for phylogenetics. PCR protocols, a guide to methods and application 315-322. https://doi.org/10.1016/B978-0-12-372180-8.50042-1

Yang Q, Du Z, Tian CM (2018) Phylogeny and morphology reveal two new species of Diaporthe from Traditional Chinese Medicine in Northeast China. Phytotaxa 336: 159-170. https://doi.org/10.11646/phytotaxa.336.2.3

Yang Q, Jiang N, Tian CM (2020) Three new Diaporthe species from Shaanxi province, China. MycoKeys 67: 1-18. https://doi.org/10.3897/mycokeys.67.49483

Zhang QM, Yu CL, Li GF, Wang CX (2018) First report of Diaporthe eres causing twig canker on Zizyphus jujuba (Jujube) in China. Plant Disease 102: e1458. https://doi.org/10.1094/ PDIS-12-17-1910-PDN

Zhang Z, Zhang ZB, Huang YT, Wang FX, Hu WH, Dai LY, Zhong J, Liu Y, Zhu JZ (2021) First report of Diaporthe hongkongensis causing fruit rot on peach (Prunus persica) in China. Plant Disease. https://doi.org/10.1094/PDIS-07-20-1505-PDN

\section{Supplementary material I}

\section{GenBank accession numbers of isolates included in this study}

Author: Xianhong Wang

Data type: GenBank accession numbers

Explanation note: GenBank accession numbers of sequences obtained from this study. Copyright notice: This dataset is made available under the Open Database License (http://opendatacommons.org/licenses/odbl/1.0/). The Open Database License $(\mathrm{ODbL})$ is a license agreement intended to allow users to freely share, modify, and use this Dataset while maintaining this same freedom for others, provided that the original source and author(s) are credited.

Link: https://doi.org/10.3897/mycokeys.80.63816.suppl1

\section{Supplementary material 2}

List of Diaporthe species used to phylogenetic analysis in this study, with details about host, country, and GenBank accession numbers

Author: Xianhong Wang

Data type: GenBank accession numbers

Explanation note: GenBank accession numbers of sequences downloaded from GenBank. Copyright notice: This dataset is made available under the Open Database License (http://opendatacommons.org/licenses/odbl/1.0/). The Open Database License $(\mathrm{ODbL})$ is a license agreement intended to allow users to freely share, modify, and use this Dataset while maintaining this same freedom for others, provided that the original source and author(s) are credited.

Link: https://doi.org/10.3897/mycokeys.80.63816.suppl2 